\title{
Invited Paper: Eliminate, Abandon, Dismantle: Cataloging in Library Consultant Reports
}

\author{
Tina Gross \\ 1038 17th Ave South \# 1, Saint Cloud, MN 56301, \\ <tmgross@stcloudstate.edu>
}

Gross, Tina. Invited Paper: Eliminate, Abandon, Dismantle: Cataloging in Library Consultant Reports. Knowledge Organization. 39(5), 398-399. 1 reference.

\section{Extended Abstract}

If you worked in an academic library in 2012, you probably read the report Redefining the Academic Library: Managing the Migration to Digital Information Services (UAL 2011). There's a good chance that you were asked to participate in discussions organized around it. It was circulated widely and hailed as a seminal report, with very little criticism or disagreement expressed in public venues.

The report has strengths, such as its overview of the problems impeding the provision of access to ebooks and its advocacy of embedding librarians in courses and departments. Its discussion of scholarly communication models presents open access as a positive and necessary development.

From an information organization perspective, however, it is abysmal. It says nothing about the future or "redefining" of cataloging and metadata in academic libraries, other than advocating that they outsource cataloging entirely.

Overall, the report is characterized by the exultation of leanness and austerity, encouraging libraries to accommodate themselves to greatly reduced budgets and to view this as visionary and innovative. The library services that the report presents as relevant to meeting the needs of current and future users are ones already welcomed by most librarians, but it sharply counterposes the implementation of these services with the continuation of those it designates as "lowimpact" activities, such as cataloging. It makes sweeping recommendations that, if implemented, could mean the demise not just of cataloging and metadata creation in academic libraries, but also of collection building and traditional reference services provided by librarians based at the user's own institution.

Despite the fact that the cataloging and library metadata community is bustling with discussion and debate about its future, it has made little response to this report. Whatever the reasons for this, the community needs to be ready to take advantage of any opportunity to engage colleagues about the role of information organization in libraries and the ways in which it ought to evolve, and to address misconceptions and false assumptions that have the potential to influence administrators.

In the spirit of developing a consistent framework, what follows is a proposed series of questions (perhaps the beginnings of a checklist) that catalogers should attempt to answer when analyzing and responding to consultant's reports. They are posed here to Redefining the Academic Library.

What does this report say about innovation and advances in cataloging?

One might expect some reference to linked data, $\mathrm{RDA}$, and FRBR, or to the replacement of MARC format, but none of these are even mentioned. The only "innovation" or "advance" discussed is for libraries to stop doing it.

What role does this report maintain or assume that libraries should have in producing the metadata they use?

The report urges academic libraries to approach cataloging as something we pay others to do, not as something we do. It says (UAL 2011, xii), 
T. Gross. Invited Paper: Eliminate, Abandon, Dismantle: Cataloging in Library Consultant Reports

As one contact put it, "We don't need a thousand different descriptions of the same book." The ability to standardize and share basic cata$\log$ entries for almost all holdings eliminates much of the need for dedicated catalogers in academic libraries. Books can now be purchased "shelf-ready" from vendors, arriving fully processed and ready to lend to patrons.

By "a thousand different descriptions," are they referring to copy cataloging with time-consuming local modifications, or do they think that every library creates its own description of each book? Do they think the ability to standardize and share basic catalog entries is a recent development, or that it has no connection to the existence of dedicated catalogers in academic libraries? Do they believe that vendor prices will stay the same if they have to create all of the records themselves?

How does this report address the impact of the quality of cataloging/metadata on users?

In reference to the limitations of the Espresso Book Machine, it says "Poor metadata in existing catalog makes discovery difficult" (UAL 2011, 32).

There's no recognition that this is often a problem with catalog records provided by vendors.

Does this report present the discontinuation of activities or cutting of services as innovation?

Yes, particularly in presenting the new library at UC Merced as having been able to "jump directly into the lean, flexible end state" that it advocates. The overview provided of this desirable end state emphasizes reduced or discontinued services, including "Minimal physical collection," "No subject librarians on staff," "Outsourced technical services," "No reference desk," and "Outsourced reference service through phone, e-mail, chat and workshops" (UAL 2011, 18).
Does this report propose a model that's sustainable if adopted by all/most libraries?

Despite indicating the UC Merced is dependent on resources and services provided by other libraries (it is able to have a minimal physical collection because its users have access to massive collections at other UC institutions; outsourcing reference and technical services is possible because other libraries contribute to the staffing of services like QuestionPoint and create many of the catalog records that are sold by vendors), the report asserts that "UC Merced symbolizes a fundamentally different future for libraries at all levels, and provides proof that such a future is indeed viable even at research institutions" (UAL 2011, 18).

This report recommends a parasitical relationship to the rest of library community, but says nothing about how this model could be sustained if all academic libraries adopted it.

Does this report present austerity as immutable?

Budget cuts, lack of resources, and more and more austerity with no end in sight are assumed. Taking austerity for granted and embracing it eagerly is presented as, in itself, progressive and bold. There is no inkling that challenging, resisting, or even questioning budget cuts might be possible. The reasons for which austerity is being imposed on academic libraries (and universities) are assumed to be legitimate and indisputable.

\section{Reference}

University Leadership Council. 2011. Redefining the academic library: managing the migration to digital information services. Available http://www.educa tionadvisoryboard.com/pdf/23634-EAB-Redefining -the-Academic-Library.pdf. 


\title{
KNOWLEDGE ORGANIZATION
}

\author{
Official Bi-Monthly Journal of the International Society for Knowledge Organization \\ ISSN $0943-7444$ \\ International Journal devoted to Concept Theory, Classification, Indexing and Knowledge Representation
}

\author{
Publisher \\ ERGON-Verlag GmbH, Keesburgstr. 11, D-97074 Würzburg \\ Phone: +49 (0)931 280084; FAX + 49 (0)931 282872 \\ E-mail: service@ergon-verlag.de; http://www.ergon-verlag.de
}

\section{Editor-in-chief (Editorial office)}

Dr. Richard P. SMIRAGLIA (Editor-in-Chief), School of Information Studies, University of Wisconsin, Milwaukee, Northwest Quad Building B, 2025 E Newport St., Milwaukee, WI 53211 USA. E-mail: smiragli@uwm.edu

\section{Instructions for Authors}

Manuscripts should be submitted electronically (in Word or RTF format) in English only via email to the editor-in chief and should be accompanied by an indicative abstract of 100 to 200 words.

A separate title page should include the article title and the author's name, postal address, and E-mail address, if available. Only the title of the article should appear on the first page of the text.

To protect anonymity, the author's name should not appear on the manuscript, and all references in the body of the text and in footnotes that might identify the author to the reviewer should be removed and cited on a separate page. Articles that do not conform to these specifications will be returned to authors.

Criteria for acceptance will be appropriateness to the field of the journal (see Scope and Aims), taking into account the merit of the contents and presentation. The manuscript should be concise and should conform as much as possible to professional standards of English usage and grammar. Manuscripts are received with the understanding that they have not been previously published, are not being submitted for publication elsewhere, and that if the work received official sponsorship, it has been duly released for publication. Submissions are refereed, and authors will usually be notified within 6 to 10 weeks.

The text should be structured by numbered subheadings. It should contain an introduction, giving an overview and stating the purpose, a main body, describing in sufficient detail the materials or methods used and the results or systems developed, and a conclusion or summary.

Footnotes are not permitted; all narration should be included in the text of the article.

Italics should not be used for emphasis. Em-dashes should be used as substitutes for commas. Paragraphs should include a topic sentence and some developed narrative. A typical paragraph has several sentences.

Reference citations within the text should have the following form: (author year). For example, (Jones 1990). Specific page numbers are required for quoted material, e.g. (Jones 1990, 100). A citation with two authors would read (Jones and Smith, 1990); three or more authors would be: (Jones et al., 1990). When the author is mentioned in the text, only the date and optional page number should appear in parenthesis - e.g. According to Jones (1990), ...

References should be listed alphabetically by author at the end of the article. Author names should be given as found in the sources (not abbreviated). Journal titles should not be abbreviated.
Multiple citations to works by the same author should be listed chronologically and should each include the author's name. Articles appearing in the same year should have the following format: "Jones 2005a, Jones 2005b, etc." Issue numbers are given only when a journal volume is not through-paginated.

Examples:

Dahlberg, Ingetraut. 1978. A referent-oriented, analytical concept theory for INTERCONCEPT. International classification 5: $142-51$.

Howarth, Lynne C. 2003. Designing a common namespace for searching metadata-enabled knowledge repositories: an international perspective. Cataloging E classification quarterly $37 \mathrm{n} 1 / 2$ : 173-85.

Pogorelec, Andrej and Šauperl, Alenka. 2006. The alternative model of classification of belles-lettres in libraries. Knowledge organization 33: 204-14.

Schallier, Wouter. 2004. On the razor's edge: between local and overall needs in knowledge organization. In McIlwaine, Ia C. ed., Knowledge organization and the global information society: Proceedings of the Eighth International ISKO Conference 13-16 July 2004 London, UK. Advances in knowledge organization 9. Würzburg: Ergon Verlag, pp. 269-74.

Smiraglia, Richard P. 2001. The nature of 'a work': implications for the organization of knowledge. Lanham, Md.: Scarecrow.

Smiraglia, Richard P. 2005. Instantiation: Toward a theory. In Vaughan, Liwen, ed. Data, information, and knowledge in a networked world; Annual conference of the Canadian Association for Information Science ... London, Ontario, June 2-4 2005. Available http://www.cais-acsi.ca/2005proceedings.htm.

Illustrations should be kept to a necessary minimum and should be embedded within the document. Photographs (including color and half-tone) should be scanned with a minimum resolution of $600 \mathrm{dpi}$ and saved as .jpg files. Tables and figures should be embedded within the document. Tables should contain a number and title at the bottom, and all columns and rows should have headings. All illustrations should be cited in the text as Figure 1, Figure 2, etc. or Table 1, Table 2, etc.

Upon acceptance of a manuscript for publication, authors must provide a wallet-size photo and a one-paragraph biographical sketch (fewer than 100 words). The photograph should be scanned with a minimum resolution of $600 \mathrm{dpi}$ and saved as a .jpg file.

\section{Advertising}

Responsible for advertising: ERGON-Verlag GmbH, Keesburgstr. 11, 97074 Würzburg (Germany).

(C) 2012 by ERGON-Verlag GmbH.

All Rights reserved.

KO is published bi-monthly by ERGON-Verlag GmbH.

- The price for the print version is $€ 198,00$ /ann. including airmail delivery.

- The price for the print version plus access to the online version (PDF) is $€ 229,00 / a n n$. including airmail delivery. 


\title{
$\mathrm{KO}$
}

\section{KNOWLEDGE ORGANIZATION}

\author{
Official Bi-Monthly Journal of the International Society for Knowledge Organization \\ ISSN $0943-7444$ \\ International Journal devoted to Concept Theory, Classification, Indexing and Knowledge Representation
}

\section{Scope}

The more scientific data is generated in the impetuous present times, the more ordering energy needs to be expended to control these data in a retrievable fashion. With the abundance of knowledge now available the questions of new solutions to the ordering problem and thus of improved classification systems, methods and procedures have acquired unforeseen significance. For many years now they have been the focus of interest of information scientists the world over.

Until recently, the special literature relevant to classification was published in piecemeal fashion, scattered over the numerous technical journals serving the experts of the various fields such as:

\author{
philosophy and science of science \\ science policy and science organization \\ mathematics, statistics and computer science \\ library and information science \\ archivistics and museology \\ journalism and communication science \\ industrial products and commodity science \\ terminology, lexicography and linguistics
}

Beginning in 1974, KNOWLEDGE ORGANIZATION (formerly INTERNATIONAL CLASSIFICATION) has been serving as a common platform for the discussion of both theoretical background questions and practical application problems in many areas of concern. In each issue experts from many countries comment on questions of an adequate structuring and construction of ordering systems and on the problems of their use in opening the information contents of new literature, of data collections and survey, of tabular works and of other objects of scientific interest. Their contributions have been concerned with

(1) clarifying the theoretical foundations (general ordering theory/science, theoretical bases of classification, data analysis and reduction)

(2) describing practical operations connected with indexing/classification, as well as applications of classification systems and thesauri, manual and machine indexing

(3) tracing the history of classification knowledge and methodology

(4) discussing questions of education and training in classification

(5) concerning themselves with the problems of terminology in general and with respect to special fields.

\section{Aims}

Thus, KNOWLEDGE ORGANIZATION is a forum for all those interested in the organization of knowledge on a universal or a domain-specific scale, using concept-analytical or concept-synthetical approaches, as well as quantitative and qualitative methodologies. KNOWLEDGE ORGANIZATION also addresses the intellectual and automatic compilation and use of classification systems and thesauri in all fields of knowledge, with special attention being given to the problems of terminology.

KNOWLEDGE ORGANIZATION publishes original articles, reports on conferences and similar communications, as well as book reviews, letters to the editor, and an extensive annotated bibliography of recent classification and indexing literature.

KNOWLEDGE ORGANIZATION should therefore be available at every university and research library of every country, at every information center, at colleges and schools of library and information science, in the hands of everybody interested in the fields mentioned above and thus also at every office for updating information on any topic related to the problems of order in our information-flooded times.

KNOWLEDGE ORGANIZATION was founded in 1973 by an international group of scholars with a consulting board of editors representing the world's regions, the special classification fields, and the subject areas involved. From 1974-1980 it was published by K.G. Saur Verlag, München. Back issues of 1978-1992 are available from ERGON-Verlag, too.

As of 1989, KNOWLEDGE ORGANIZATION has become the official organ of the INTERNATIONAL SOCIETY FOR KNOWLEDGE ORGANIZATION (ISKO) and is included for every ISKO-member, personal or institutional in the membership fee (US \$ 55/US \$ 110).

Rates: From 2011 on for 6 issues/ann. (including indexes) $€ 198,00$ (forwarding costs included) for the print version resp. $€ 229,00$ for the print version plus access to the online version (PDF). Membership rates see above.

ERGON-Verlag GmbH, Keesburgstr. 11, D-97074 Würzburg; Phone: +49 (0)931 280084; FAX +49 (0)931 282872; E-mail: service@ergon-verlag.de; http://www.ergon-verlag.de

The contents of this journal are indexed and abstracted in Referativnyi Zhurnal Informatika and in the following online databases: Information Science Abstracts, INSPEC, Library and Information Science Abstracts (LISA), Library Literature, PASCAL, Sociological Abstracts, and Web Science \& Social Sciences Citation Index. 


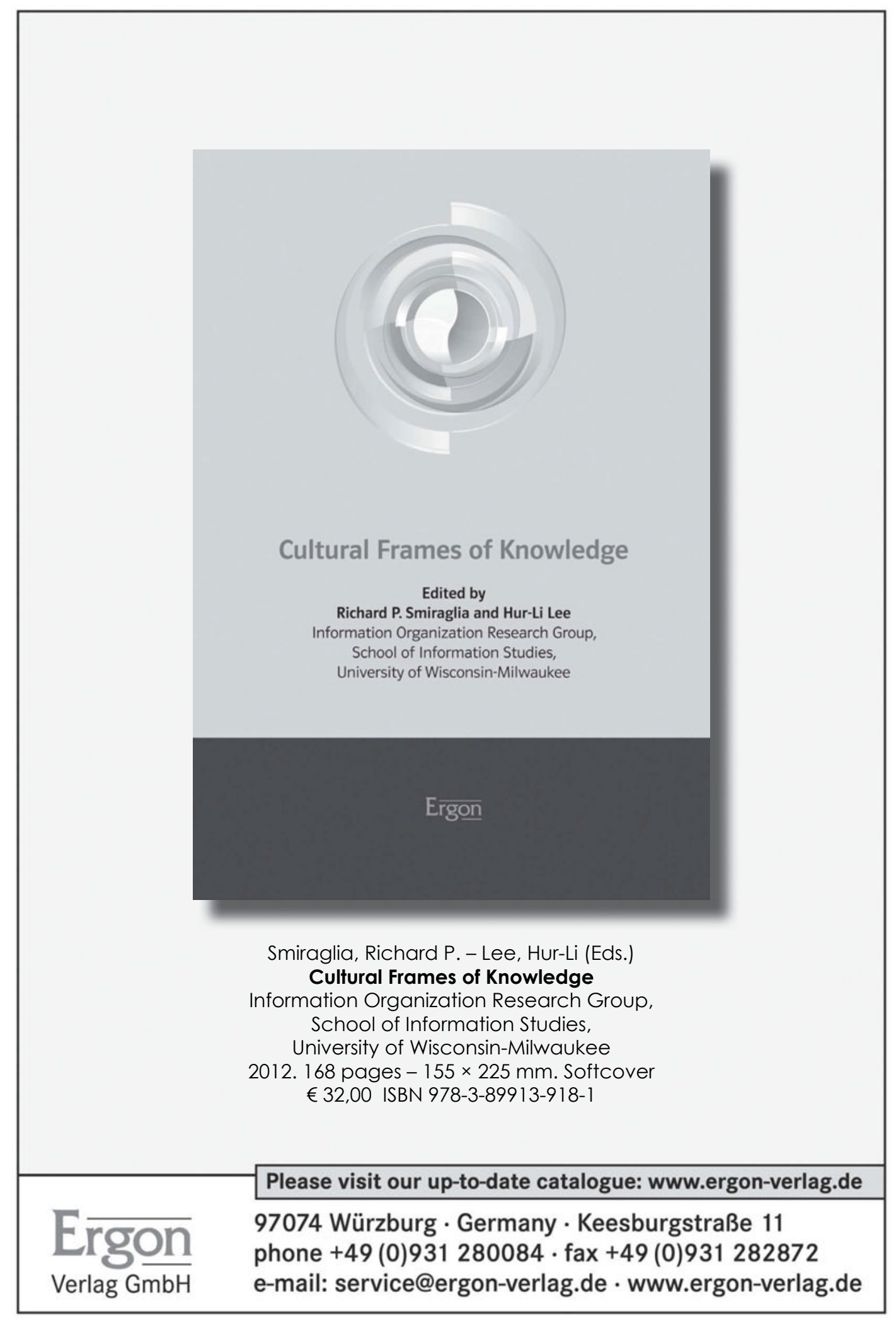

